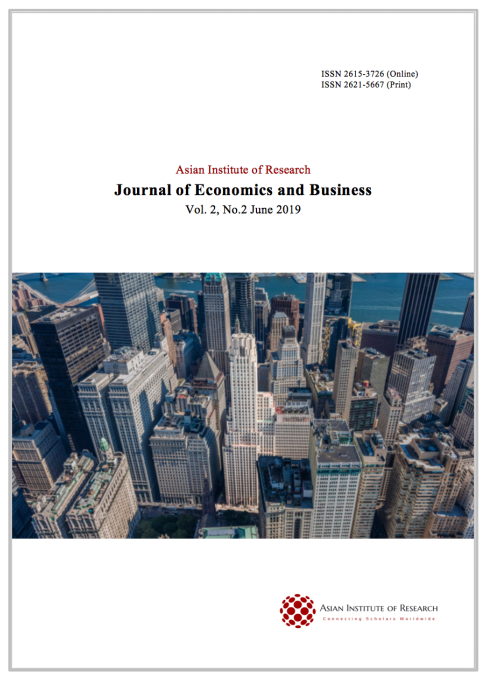

\title{
Journal of Economics and Business
}

\author{
Zhou, Jia-Yan, Pan, Wen-Tsao, and Zhuang, Mei-Er. (2019), Research on \\ Housing Price Factors of Zhuhai City: Under the background of the Opening of \\ Hong Kong - Zhuhai - Macao Bridge. In: Journal of Economics and Business, \\ Vol.2, No.2, 448-458.
}

ISSN 2615-3726

DOI: 10.31014/aior.1992.02.02.100

The online version of this article can be found at: https://www.asianinstituteofresearch.org/

Published by:

The Asian Institute of Research

The Journal of Economics and Business is an Open Access publication. It may be read, copied, and distributed free of charge according to the conditions of the Creative Commons Attribution 4.0 International license.

The Asian Institute of Research Journal of Economics and Business is a peer-reviewed International Journal. The journal covers scholarly articles in the fields of Economics and Business, which includes, but not limited to, Business Economics (Micro and Macro), Finance, Management, Marketing, Business Law, Entrepreneurship, Behavioral and Health Economics, Government Taxation and Regulations, Financial Markets, International Economics, Investment, and Economic Development. As the journal is Open Access, it ensures high visibility and the increase of citations for all research articles published. The Journal of Economics and Business aims to facilitate scholarly work on recent theoretical and practical aspects of Economics and Business. 


\title{
Research on Housing Price Factors of Zhuhai City : Under the background of the Opening of Hong Kong - Zhuhai - Macao Bridge
}

\author{
Jia-Yan Zhou', Wen-Tsao Pan', Mei-Er Zhuang ${ }^{1}$
}

${ }^{1}$ School of Business, Guangdong University of Foreign Studies, Guangzhou, 510006, China

Correspondence: Wen-Tsao Pan. Email: teacherp0162@126.com

\begin{abstract}
The completion and opening of the Hongkong-Zhuhai-Macao Bridge not only strengthened the links between different cities in the Pearl River Delta region but also greatly promoted economic exchanges between Hong Kong and Macao and the Mainland. In theory, the facilitation of traffic conditions can drive economic development around it, especially in the area of real estate, which may have a regional housing price convergence effect. Taking Zhuhai real estate industry as the research object, this paper selects 39 communities in Xiangzhou District (including Hengqin New District) as samples, based on the Hedonic model. And through the method of Equal Part Linear Regression Model to establish the functional relationship between the housing price of Zhuhai and the location factors, neighborhood factors and other influencing factors, to find out the main factors affecting Zhuhai housing prices after the opening of the Hong Kong-Zhuhai-Macao Bridge. The results show that for the Xiangzhou District of Zhuhai, the distance from the sea is an important factor affecting housing prices, showing a significant negative correlation. However, other general factors affecting house prices play a relatively small role.
\end{abstract}

Keywords: Hong Kong-Zhuhai-Macao Bridge, Real Estate Industry, Zhuhai, Hedonic Model, Equal Part Linear Regression Model

\section{Introduction}

Since the opening of the Hong Kong-Zhuhai-Macao Bridge, the housing prices in Zhuhai has been closely watched by the local government and the public. Price theory believes that the factors affecting housing prices work through the relationship between supply and demand. The market price is actually the equilibrium price corresponding to the intersection of the supply curve and the demand curve. Many scholars at home and abroad also use this theory to analyze the factors affecting housing prices. Huang Houxia and Hou Liying (2010) believe that from the point of view of demand, the fluctuation of housing prices is mainly affected by factors such as economy, population, finance, psychology, leasing, and macroeconomic regulation. And from the perspective of supply, the factors affecting housing price fluctuations mainly include Location, real estate brand, and housing supply structure ${ }^{[1]}$. Specifically, some scholars use Factor Analysis to conclude that economic factors are the major factors affecting housing prices (Li Chen, 2010) ${ }^{[2]}$. Zhang Jiaping (2008) pointed out that the real exchange rate of RMB positively affects housing prices by establishing a cointegration model ${ }^{[3]}$. From a cost perspective, land price are an important 
component of housing prices. Yan Lei (2011) used the panel data analysis from 1997 to 2008 to obtain a significant positive correlation between house prices and land prices ${ }^{[4]}$. However, there are domestic scholars, such as Yao Xianguo and Huang Yuhua (2001), who have proposed that there is no direct linear correlation between land prices and housing prices ${ }^{[5]}$. Of course, in addition to supply, demand and cost, property management, building materials, and other factors also play a decisive role in housing prices. Jin Xiaobin, Yin Shaomei, Yin Xiaoning, and Zhou Yikang (2004) pointed out that housing prices will be affected by factors such as population changes and government policy regulation ${ }^{[6]}$. Han Yi (2004) believes that property management affects the prices in the primary real estate market by transmitting information about corporate projects to consumers ${ }^{[7]}$. Feng Wen and Wu Hao (2006) pointed out that the main building materials will affect housing prices ${ }^{[8]}$. Generally speaking, there are many academic studies on housing prices, many of which have conducted in-depth analysis and exploration of different factors affecting housing prices.

With regard to the impact of the Hong Kong-Zhuhai-Macao Bridge on real estate in Zhuhai, the research literature related to housing prices is still scant. In the existing literature, Zhang Huawei (2016) believes that with the opening of the Hong Kong-Zhuhai-Macao Bridge, Zhuhai's real estate products will move towards diversification, and the proportion of foreign visitors will be large and larger. At the same time, he also pointed out that the demand for the real estate market in Zhuhai will continue to increase, especially for commercial buildings, which will bring more economic benefits to the market ${ }^{[9]}$. Chen Zhangxi and Mao Yan (2018) reached the following conclusions by constructing a real-estate spatial interaction model between Hong Kong, Macao, and Zhuhai: After the opening of the Hong Kong-Zhuhai-Macao Bridge, the spatial interaction between the two will increase significantly. Among them, Zhuhai has a large influence and influence range, and it is more attractive to Hong Kong residents than Maca ${ }^{[10]}$. Undoubtedly, the opening of the Hong Kong-Zhuhai-Macao Bridge has shortened the time and space between Hong Kong, Macau, and Zhuhai, enhancing the location and social and economic development of the three. Coupled with a beautiful and livable environment, Zhuhai's housing prices and market demand should be improved.

Real estate has a high heterogeneity, which means that even at the same time, housing prices will be different, due to location, policy, neighborhood characteristics, and other factors. In order to explore the effect of different real estate characteristics on Zhuhai's housing prices, this paper selects the second-hand data of residential areas in Xiangzhou District (including Hengqin New District) in Zhuhai City in 2018, and uses the equal part linear regression method proposed by Pan Wenchao (2017) for data analysis, so as to obtain the difference in the impact of different real estate characteristics on housing prices since the opening of the Hong Kong-Zhuhai-Macao Bridge $^{[11]}$.

\section{Research Method}

\subsection{Equal Part Linear Regression}

In this paper, we adopt the Multiple Equal Part Linear Regression Model (EPLRM) which proposed by Pan Wenchao (2017) ${ }^{[10]}$. It can divide the analysis data into several equal parts and build the linear regression model, respectively. In this way, the trend of each equal parts can be independently observed. Also, it can be compared with the standard linear regression. By using this method, we can learn that whether there will be undervalued or overvalued if using least square regression analysis and find out the real factors that influence the real estate price.

\subsubsection{Equal Part Linear Theory}

Assume $\mathrm{Y}$ is a continuous dependent variable dependent on $\mathrm{X}$. The analysis data is divided into several equal parts and built a fit linear regression model for the different equal parts. These three linear regression equations can be expressed as:

$$
y_{i}=\beta_{0}+\beta_{1} x_{i}+\varepsilon_{i}
$$

The error term $\varepsilon_{\text {i }}$ obeys a normal distribution with a mean $\mu$ of 0 and a standard deviation $\sigma^{2}$ of 2 . Since linear regression is based on the least squares method to minimize the sum of squared deviations, it can be written as: 


$$
\min \sum_{i}\left[y_{i}-\left(\beta_{0}+\beta_{1} x_{i}\right)\right]^{2}
$$

The values of $\beta_{0}$ and $\beta_{1}$ can be solved according to the standard equation. The specific results are as follows:

$$
\begin{gathered}
\widehat{\beta}_{0}=\frac{\sum_{i=1}^{n}\left(x_{i}-\bar{x}\right)\left(y_{i}-\bar{y}\right)}{\sum_{i=1}^{n}\left(x_{i}-\bar{x}\right)^{2}} \\
\widehat{\beta}_{1}=y-\bar{\beta}_{0} \bar{x}
\end{gathered}
$$

The closeness of the linear regression model to each observation point is called the goodness of fit of the linear regression model and the data, while the judgment coefficient $R^{2}$ is a measure of the goodness of fit. The calculation formula is:

$$
R^{2}=\frac{\sum_{i=1}^{n}\left(y_{i}-\overline{\bar{y}}\right)^{2}}{\sum_{i=1}^{n}\left(y_{i}-\bar{y}\right)^{2}}
$$

The value range of $R^{2}$ is [0,1], and the larger the $R^{2}$ is, the better the goodness of fit of the regression model is, that is, the more the part of the $\mathrm{Y}$ value is explained by the change of X. When $R^{2}=1$, the sum of the squares of the regression is equal to the sum of the squares, indicating that the regression model has no residuals and is completely suitable. When $R^{2}=0$, the sum of squared residuals is equal to the sum of squares, indicating that the regression model has no explanatory power for $\mathrm{Y}$.

The confidence interval for $\beta_{1}$ at the confidence level of $(1-\alpha)$ is:

$$
\left(\widehat{\beta}_{i}-t_{\alpha / 2} \times s_{\hat{\beta}_{t}}, \hat{\beta}_{i}+t_{\alpha / 2} \times s_{\hat{\beta}_{t}}\right), i=0,1
$$

Different from the general linear regression model, the equal part linear regression model divides the data into "

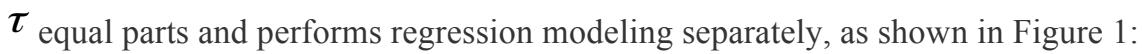

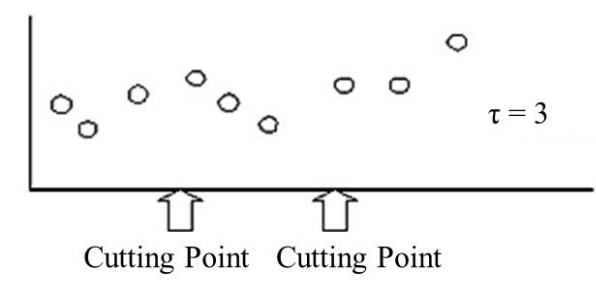

Figure 13 Equal Part Linear Regression Models

In this figure, the linear data is divided into 3 equal parts, and there exist 3 sample data points in each equal part. Because there are different trends in the data of the three sample points in each equal part, prediction or analysis using standard linear regression may result in distortion. The equal part linear regression formula is:

$$
y_{i}^{\tau}=\beta_{0}^{\tau}+\beta_{1}^{\tau} X_{i}^{\tau}+\varepsilon_{i}^{\tau}
$$

The minimum evaluation formula is:

$$
\begin{gathered}
\hat{\beta}_{0}^{\tau}=\frac{\sum_{i=1}^{n}\left(x_{i}^{\tau}-\bar{x}^{\tau}\right)\left(y_{i}{ }^{\tau}-\bar{y}^{\tau}\right)}{\sum_{i=1}^{n}\left(x_{i}{ }^{\tau}-\bar{x}^{\tau}\right)^{2}} \\
\hat{\beta}_{1}{ }^{\tau}=\bar{y}^{\tau}-\bar{\beta}_{0}{ }^{\tau} \bar{x}^{\tau}
\end{gathered}
$$


Decision coefficient and confidence interval:

\subsubsection{Equal Part Linear Regression Coefficient and Confidence Interval}

The equal parted linear regression models the equal part sample point data from left to right and records the coefficients and confidence intervals of the regression, as shown in picture 2 :

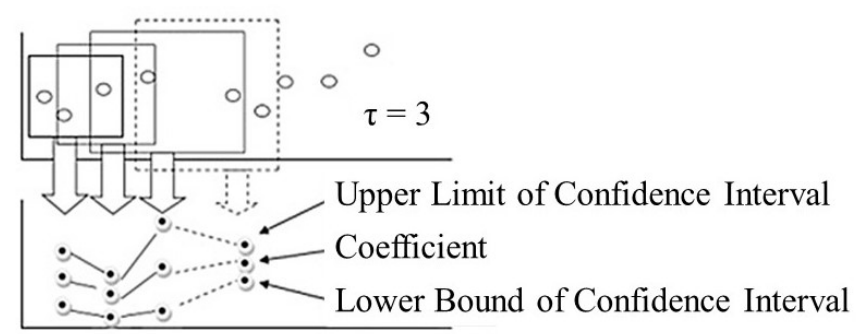

Figure 23 Equal Part Linear Regression Lines and Confidence Intervals

\section{Data and Model}

\subsection{Research Material}

This paper takes Zhuhai's residential community as the research object. Because the Xiangzhou District (including Hengqin New District) is geographically close to the Hong Kong-Zhuhai-Macao Bridge, it is greatly affected by the Hong Kong-Zhuhai-Macao Bridge. Therefore, this paper selects the new real estate opened in Xiangzhou District in recent years as sample data. The sample data mainly comes from the real estate information website of Fangtianxia Real Estate Network and anjuke.com, and the price of each property is taken as the average price in October and November of 2018.

\subsection{Research Model}

\subsubsection{Characteristic Price Model}

The characteristic price method considers that housing prices are determined by different attributes and the utility that people obtain from the attributes. The additional cost that a consumer is willing to pay for each unit of an attribute of a property is the implied price (characteristic price) of that attribute, which indicates how much each attribute contributes to the price. Butler theory holds that the price of real estate is mainly influenced by three characteristic variables: location characteristics, neighborhood features, and architectural features.

The function of the characteristic price model known as Hedonic model is:

$$
P=f\left(X_{1}, X_{2}, X_{3}, \ldots \ldots, X_{n}\right)
$$

In practical applications, it can be turned into a linear form, where $\mathrm{P}$ represents the characteristic price, $\mathrm{X}_{\mathrm{n}}$ represents the characteristic variable of the residential cell, $\alpha$ is a constant term, and $\varepsilon$ is an error term:

$$
P=\alpha+\beta_{1} X_{1}+\beta_{2} X_{2}+\beta_{3} X_{3}+\cdots \cdots+\beta_{\mathrm{n}} X_{\mathrm{n}}+\varepsilon
$$

\subsubsection{Selection and Quantification of Variables}

The variables selected in this paper and their quantification are shown in Table 1. 
Table 1 Quantification of Selected Variables

\begin{tabular}{|c|c|c|}
\hline & Characteristic Variable & Quantification of Variables \\
\hline \multirow{4}{*}{$\begin{array}{l}\text { Location } \\
\text { Characteristic } \\
\text { Variable }\end{array}$} & $\begin{array}{l}\text { Distance from Hong Kong- } \\
\text { Zhuhai-Macao Bridge }\end{array}$ & $\begin{array}{l}\text { Actual distance from the property to the Hong Kong- } \\
\text { Zhuhai-Macao Bridge }(\mathrm{km})\end{array}$ \\
\hline & Distance from the sea & $\begin{array}{l}\text { The actual distance from the property to the nearest sea } \\
\text { area }(\mathrm{km})\end{array}$ \\
\hline & Traffic condition & $\begin{array}{l}\text { The number of traffic lines within } 500 \text { meters around } \\
\text { the property }\end{array}$ \\
\hline & $\begin{array}{l}\text { Time required to drive to Hong } \\
\text { Kong-Zhuhai-Macao Bridge }\end{array}$ & $\begin{array}{l}\text { Usually, the actual time required to drive from the } \\
\text { property to the Hong Kong-Zhuhai-Macao Bridge } \\
\text { (min) }\end{array}$ \\
\hline $\begin{array}{l}\text { Neighborhood } \\
\text { Characteristic } \\
\text { Variable }\end{array}$ & $\begin{array}{l}\text { Commercial, hospital and } \\
\text { educational facilities }\end{array}$ & $\begin{array}{l}\text { The cultural, sports and educational facilities within } \\
\text { 1,000 meters around the property, including } \\
\text { supermarkets, restaurants, entertainment, banks, parks, } \\
\text { kindergartens, primary schools, junior high schools }\end{array}$ \\
\hline $\begin{array}{l}\text { Architectural } \\
\text { Characteristic } \\
\text { Variable }\end{array}$ & Community size & The total floor area of the entire property $\left(\mathrm{m}^{2}\right)$ \\
\hline Other Variables & Developer visibility & $\begin{array}{c}\text { According to the ranking of "2018 Zhuhai Real Estate } \\
\text { Development Company" from zhuhai.anjuke.com and } \\
\text { "2018 China Real Estate Top 500." }\end{array}$ \\
\hline
\end{tabular}

\section{Empirical Analysis}

\subsection{Graph Analysis}

In the empirical analysis, this article takes the housing price as the dependent variable and discusses the impact of these seven variables on the price: the distance from the Hong Kong-Zhuhai-Macao Bridge, the distance from the sea, the commercial, hospital and educational facilities, traffic conditions, community size, developer visibility and the time required to drive to Hong Kong-Zhuhai-Macao Bridge. In this paper, 39 real estates in Xiangzhou District of Zhuhai City were selected as samples, and the data were subjected to three-equal-part regression analysis. The results show that two variables have a significant impact on the housing prices in Xiangzhou District, including the distance from the sea and commercial, hospital and educational facilities. The distance from the Hong Kong-Zhuhai-Macao Bridge, the traffic situation, the popularity of the developers and the time required to drive to the Hong Kong-Zhuhai-Macao Bridge also has a certain impact on the housing prices in Xiangzhou.

Cutting 39 data points into 3 equal parts. There are 13 data in each equal part, and then a simple regression analysis is performed after moving a piece of data from left to right, and the regression coefficient and confidence interval are recorded. After moving to the far right, the recorded data is plotted in Figure 3. The results of the equal part linear regression are organized into Table 2, from left to right: the statistical value of the standard multiple linear regression (LRM), the first equal part of the equal part linear (EPLRM $\tau=1$ ), the second equal part (EPLRM $\tau=$ 2 ), third equal part (EPLRM $\tau=3$ ) statistics. From left to right, the heading lines are: the statistical value of the standard multiple linear regression (LRM), the first equal part of the equal part (EPLRM $\tau=1$ ), the second equal 
part (EPLRM $\tau=2$ ), and the third equal part (EPLRM $\tau=3$ ). According to the analysis results of standard multiple linear regression, the constant term and X2 (the distance from the sea) all reach $99 \%$ significant level, which means that $\mathrm{X} 2$ has significant explanatory power for $\mathrm{Y}$. Since the regression coefficient is negative, the distance from the sea has a significant negative impact on the housing prices of Xiangzhou District. The difference of the three equal part linear regression coefficients was subjected to F-value test, and the results were compiled into Table 3 . It can be found that in the first equal part and the second equal part, the linear regression coefficients of X1, X2, and X6 are significantly different; in the first equal part and the third equal part, the linear regression coefficients of $\mathrm{X} 2$, $\mathrm{X} 3, \mathrm{X} 6$, and $\mathrm{X} 7$ have significant differences; in the second and third divisions, the linear regression coefficients of $\mathrm{X} 1, \mathrm{X} 3$, and $\mathrm{X} 5$ are significantly different.

Combined with the above-mentioned chart, this article lists the following analysis results:

For X1, the distance from the Hong Kong-Zhuhai-Macao Bridge, the results of the operation according to Table 3 shows that there is a significant difference in the impact of the low price range and the mid-price range on the housing prices. It can be seen from Figure 3 that the distance from the Hong Kong-Zhuhai-Macao Bridge to the house price $(\mathrm{Y})$ in the mid-price range is greater than its impact on house prices in the low-price range. In addition, according to the results of Table 3, it is also known that the impact of the Hong Kong-Zhuhai-Macao Bridge on the prices of the mid-price range is significantly different from that in the high-price range. It can be seen from Figure 3 that $\mathrm{X} 1$ is underestimated if it is estimated by standard linear regression in the mid-price range, while partially overestimated in the high-price range. Therefore, on the whole, the influence of X1 on housing prices in the mid-price range is greater than the impact on housing prices in the high-price range. According to Table 2, the regression coefficient of $\mathrm{X} 1$ at the mid-price level is a positive number, indicating that for the mid-priced real estates, the farther away from the Hong Kong-Zhuhai-Macao Bridge, the higher the housing price. The regression coefficient of X1 at low-price and high-price level is negative, indicating that for low-priced and high-priced real estates, the closer the distance from Hong Kong-Zhuhai-Macao Bridge, the higher the housing prices.

For the variable X2, that is, the distance from the sea, according to the results of Table 3, the effect of the housing prices is significantly different in the low-price range and the mid-price range. It can be seen from Figure 3 that when $\mathrm{X} 2$ is in the mid-price range, if the standard linear regression is used to estimate that there will be partial underestimation, and in the low-price range, there will be more overestimation, indicating that effect of the distance from the sea in the low-price range on the housing prices is less than that in the mid-price range. In addition, the impact of the distance from the sea on housing prices is also significantly different in the low-price range and the high-price range. It can be seen from Figure 3 that $\mathrm{X} 2$ has more underestimation in the high-price range, indicating that the impact of $\mathrm{X} 2$ on housing prices at the high-price level is greater than that at the low-price level. Finally, as can be seen from Table 2, the regression coefficients of X2 at the low, medium and high price levels are all negative, indicating that for each price of real estate, there is a relationship showing the closer the distance from the sea, the higher the housing prices.

For the variable $\mathrm{X} 3$, that is, commercial, hospital, and educational facilities, if standard linear regression is used to estimate, there will be underestimation at the low, medium, and high price levels. Therefore, it can be considered that commercial, hospital, and educational support have a greater impact on housing prices. At the same time, as can be seen from Table 3, the impact of X3 on housing prices is significantly different in the low-price range and high-price range, and the impact on housing prices is also significantly different at the mid-price level and the high-price level. Combined with Figure 3, it can be seen that the impact of X1 on housing prices at the high-price level is greater than that at the low-price level, meanwhile, the impact of $\mathrm{X} 3$ on housing prices at the high-price level is also greater than that at the mid-price level. Finally, according to Table 2, the coefficients of X3 in the low-price range and the mid-price range are negative, indicating that for the low-priced and mid-priced real estates, the more commercial, hospital and educational facilities, the lower the housing prices. On the contrary, the regression coefficient of $\mathrm{X} 3$ at the high-price level is a positive number, indicating that for high-priced real estates, the more commercial, hospital and educational facilities, the higher the housing prices.

$\mathrm{X} 4$, the traffic condition, has no significant difference in linear regression coefficients between the three equals. If the standard linear regression is used to estimate, there will be an underestimation, indicating that the traffic 
situation will have a greater impact on the housing prices in Xiangzhou District. According to the different linear regression coefficients in the three equal parts, it can be concluded that the traffic condition has a negative impact on the prices of low-priced and high-priced real estates, and positively affects the price of mid-priced real estates. Because in the standard linear regression and the equal part linear regression, the coefficients of X5, the community sizes, are all 0 , indicating that the community size has no explanatory power for the housing price of Xiangzhou District.

According to the translation model, X6, the developer visibility, is underestimated in three equal parts, indicating that the developer visibility has a greater impact on the housing prices in Xiangzhou District. According to the regression coefficient of Table 2, the popularity of the developer has a negative impact on the housing prices of the low-priced and high-priced real estates, and a positive impact in the mid-price range. In addition, X6 has a significant difference in the impact on housing prices at the low-price level and the mid-price level. In combination with Figure 3, it can be seen that the underestimation of X6 at the mid-price level is significantly greater than that at the low-price level, so the influence of the developer visibility on housing prices of mid-priced real estates is greater than that of low-priced real estates.

X7, the time required to drive to the Hong Kong-Zhuhai-Macao Bridge, is underestimated in three equal parts, indicating that the time required to drive to the Hong Kong-Zhuhai-Macao Bridge has a greater impact on the housing prices in Xiangzhou District. According to the different linear regression coefficients in the three equal parts of Table 2, it can be concluded that the time required to drive to the Hong Kong-Zhuhai-Macao Bridge has a positive impact on the housing prices of low-priced and high-priced real estates, and a negative impact on the housing prices of mid-priced real estates. In addition, the regression coefficient of X7 is obviously different between the low-price level and the high-price level. It can be seen from Figure 1 that the underestimation of X7 at the high-price level is greater than that at the low-price level, that is, the impact of time required to drive to Hong Kong-Zhuhai-Macao Bridge on high-priced properties is greater than that on low-priced properties.

Table 2 Results of Equal Part Linear Regression

\begin{tabular}{|c|c|c|c|c|c|c|c|c|c|c|c|c|}
\hline & \multicolumn{3}{|c|}{$\begin{array}{c}\text { LRM } \\
\mathbf{R}^{2}=\mathbf{0 . 4 9 3}\end{array}$} & \multicolumn{3}{|c|}{$\begin{array}{c}\text { EPLRM } \tau=1 \\
R^{2}=0.691\end{array}$} & \multicolumn{3}{|c|}{$\begin{array}{c}\operatorname{EPLRM} \tau=2 \\
\mathbf{R}^{2}=\mathbf{0 . 6 2 8}\end{array}$} & \multicolumn{3}{|c|}{$\begin{array}{c}\operatorname{EPLRM} \tau=\mathbf{3} \\
\mathbf{R}^{\mathbf{2}}=\mathbf{0 . 6 1 7}\end{array}$} \\
\hline Stat. & Conf. & $\mathrm{T}$ & Sig. & Conf. & $\mathrm{T}$ & Sig. & Conf. & $\mathrm{T}$ & Sig. & Conf. & $\mathrm{T}$ & Sig \\
\hline $\mathrm{X} 1$ & -209.93 & -0.56 & - & -295.85 & -1.18 & - & 70.99 & 0.36 & - & -605.49 & -0.83 & - \\
\hline $\mathrm{X} 2$ & -1422.76 & -2.78 & $* * *$ & -563.86 & -2.03 & $*$ & -748.00 & -1.43 & - & -963.51 & -0.46 & - \\
\hline $\mathrm{X} 3$ & -47.03 & -0.60 & - & -82.94 & -1.78 & - & -106.04 & -2.23 & $*$ & 286.78 & 1.56 & - \\
\hline $\mathrm{X} 4$ & -136.49 & -0.81 & - & -22.71 & -0.15 & - & 73.77 & 0.69 & - & -148.37 & -0.47 & - \\
\hline $\mathrm{X} 5$ & 0.00 & 0.15 & - & 0.00 & -0.51 & - & 0.00 & 1.11 & - & 0.00 & -0.32 & - \\
\hline X6 & -128.62 & -1.16 & - & -95.00 & -0.99 & - & 16.74 & 0.23 & - & -167.33 & -0.72 & - \\
\hline$X 7$ & -262.53 & -1.23 & - & 8.97 & 0.06 & - & -102.11 & -0.84 & - & 195.02 & 0.47 & - \\
\hline
\end{tabular}


Note: Conf. indicates the regression coefficient, $\mathrm{T}$ indicates the $\mathrm{t}$-value, and Sig. indicates the significance.

* indicates a 90\% significant level, ** indicates a 95\% significant level, and *** indicates a 99\% significant level.
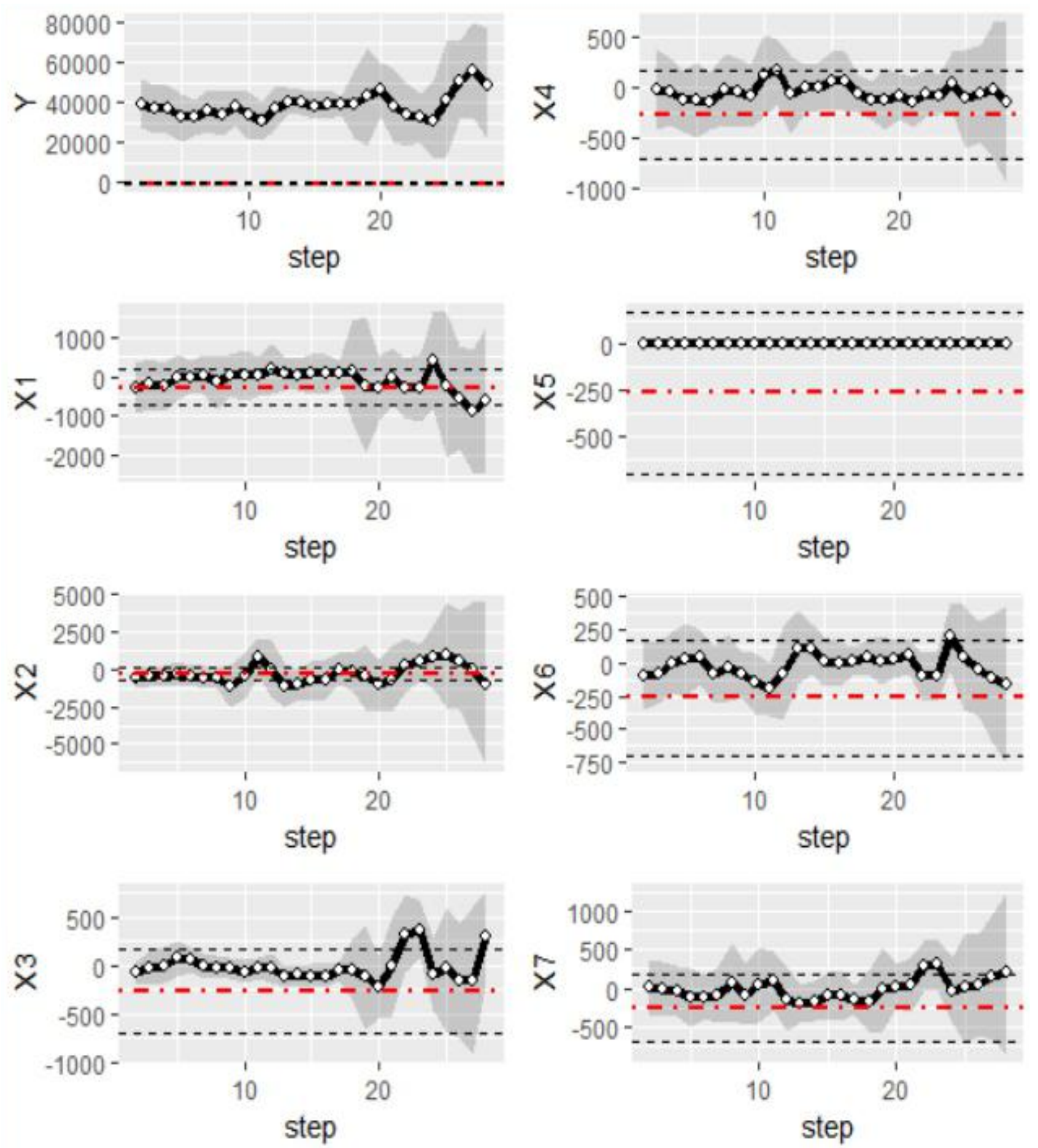

Figure 3 Results of Translation Modeling

Note: The corresponding relationship of each variable is X1 (the distance from Hong Kong-Zhuhai-Macao Bridge), X2 (the distance from the sea), X3 (commercial, hospital and educational facilities), X4 (traffic condition), X5 (community size), X6 (developer visibility), X7 (time required to drive to Hong Kong-Zhuhai-Macao Bridge) 
Table 3 F-value test results of three equal part linear regression coefficient differences

\begin{tabular}{|c|c|c|c|c|c|c|}
\hline \multirow{2}{*}{ Variable } & \multicolumn{2}{|c|}{$\tau 1-\tau 2$} & \multicolumn{2}{|c|}{$\tau 1-\tau 3$} & \multicolumn{2}{|c|}{$\tau 2-\tau 3$} \\
\hline & F-value & Sig. & F-value & Sig. & F-value & Sig. \\
\hline Constant term & 0.451 & - & 0.154 & - & 0.342 & - \\
\hline $\begin{array}{l}\text { Distance from Hong Kong- } \\
\text { Zhuhai-Macao Bridge }\end{array}$ & 9.030 & $*$ & 0.536 & - & 0.059 & $* *$ \\
\hline Distance from the sea & 0.008 & $* * *$ & 0.008 & $* * *$ & 1.009 & - \\
\hline $\begin{array}{l}\text { Commercial, hospital and } \\
\text { educational facilities }\end{array}$ & 1.326 & - & 0.031 & $* *$ & 0.023 & $* *$ \\
\hline Traffic condition & 0.326 & - & 2.289 & - & 7.028 & - \\
\hline Community size & 4.601 & - & 0.242 & - & 0.053 & $* *$ \\
\hline Developer visibility & 0.054 & $* *$ & 0.115 & * & 2.115 & - \\
\hline $\begin{array}{l}\text { Time required to drive to Hong } \\
\text { Kong-Zhuhai-Macao Bridge }\end{array}$ & 0.179 & - & 0.045 & $* *$ & 0.252 & - \\
\hline
\end{tabular}

Note: Conf. indicates the regression coefficient, $\mathrm{T}$ indicates the $\mathrm{t}$-value, and Sig. indicates the significance.

* indicates a 90\% significant level, $* *$ indicates a $95 \%$ significant level, and *** indicates a 99\% significant level.

\subsection{Cause Discussion}

The distance from the sea has a significant negative impact on housing prices. According to the results of the simple regression, the closer the house is to the sea, the higher the price. However, according to the results of the equal part linear regression, the impact of the distance from the sea to the mid-priced real estate ( $¥ 32000$-37000 / square meter) is not significant, because in this case, compared to the mid-to-high price of real estate, the price difference of the mid-priced real estate is small, and the distance from the sea is mostly between 0.3 and $1 \mathrm{~km}$, so the impact of the distance from the sea on housing prices is not obvious. For high-priced real estate (more than $¥$ 37,000 / square meter), the distance from the sea has a greater influence on housing prices. Because of the large price difference between high-priced properties, the overall situation shows that the higher the distance from the sea, the higher the housing prices, and the change between 50-500 meters from the sea is obvious. This is also in line with the general rule of the high price of sea view rooms. However, in this case, the reason why the distance from the sea does not significantly affect the house price may be a special phenomenon for some high-priced properties, such as Gree Coast and Hengyu Ink Orchid Pavilion, that is, the distance from the sea is small but the house price is low, or the distance from the sea is large, but the house price is high.

In the past studies on the factors affecting housing prices, many scholars found that traffic conditions are one of the important factors affecting housing prices. However, in this example, according to the results of simple regression and equal part linear regression, the influence of the number of bus lines on house prices is not significant, and there is no difference in the influence of real estate at various price points. This article believes that this may be caused by the following reasons: 


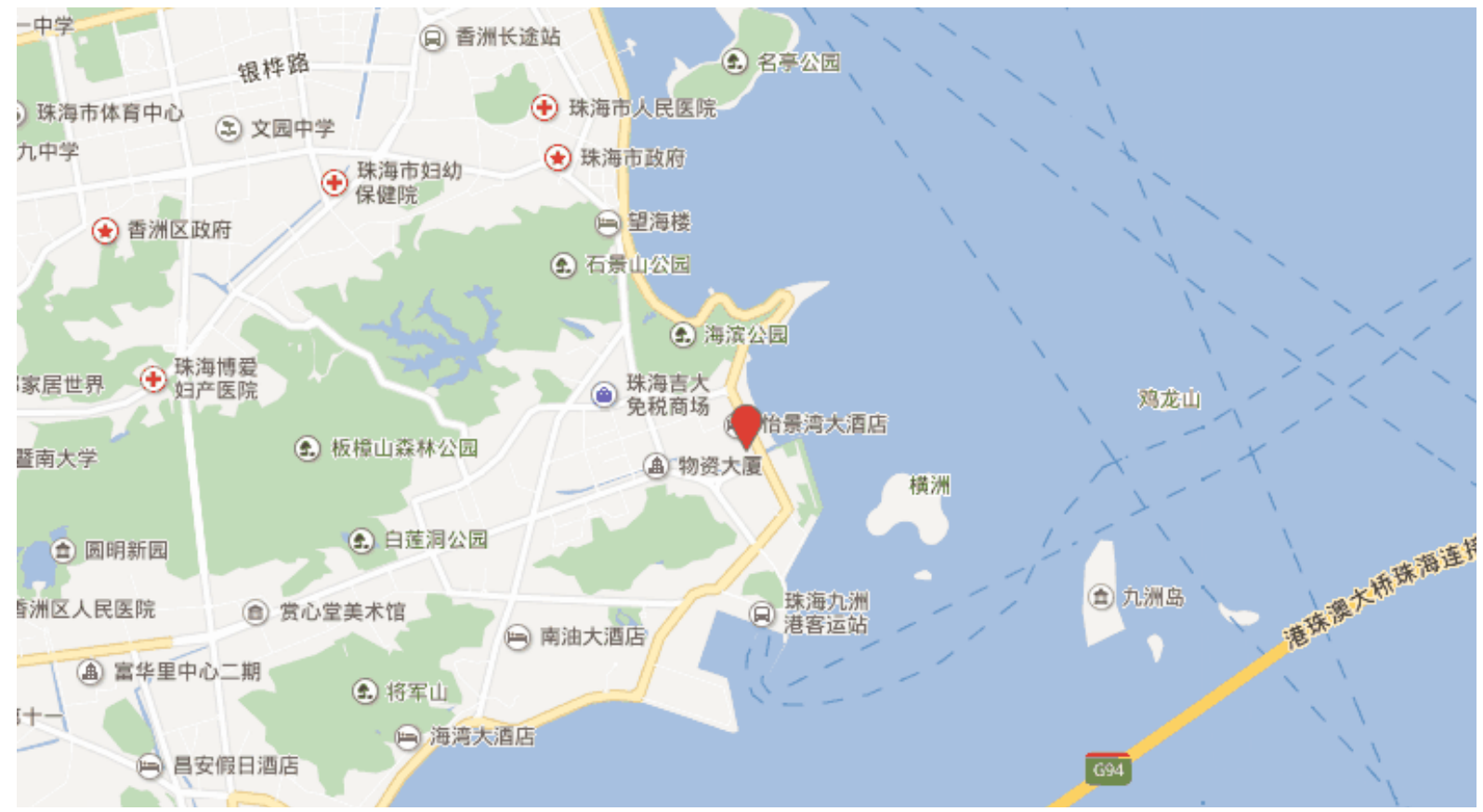

Figure 4 Xiangzhou District Map

Xiangzhou District, the core city of Zhuhai, is located on the east bank of Zhuhai City. The transportation network in Xiangzhou District extends in all directions, and after the opening of the Hong Kong-Zhuhai-Macao Bridge, Xiangzhou District has closer ties with Hong Kong and Macao. Xiangzhou District has advantages in technological innovation, investment potential, and ecological industry. It can be seen that Xiangzhou District has a higher economic level than other areas in Zhuhai. In addition, relevant data show that the average housing price in Zhuhai in Xiangzhou District in October and November 2018 was $¥ 24021$ / square meter, while the average housing price in Xiangzhou District reached $¥ 36,707$ / square meter, showing that the price level in Xiangzhou District is much higher than the average housing price of Zhuhai City. Therefore, this paper believes that under such a background, traffic conditions cannot be the main factor affecting Xiangzhou's housing prices.

According to the existing research, the better the traffic conditions in the vicinity, the higher the housing price. But the data in this article do not show such a pattern. As shown in Figure 1, there are many coastal areas in Xiangzhou District, where a lot of high-priced properties are distributed. The coastal routes only have a road name couple, so the high-priced real estate bus lines near Couple Road are less than other real estates. But such a traffic disadvantage does not affect its higher housing prices, such as Huafa International Coastal Garden, Gree Coast, Renheng Coast Center, etc. Therefore, in this case, for many properties, there is no negative correlation between the number of bus lines and housing prices.

In addition, the analysis results of this paper show that there is no correlation between the size of the community and the price level. In the data, the construction area of Cuihu Xiangshan Apartment is as high as 780000 square meters, but its housing price is only $¥ 28,000$ / square meter, far lower than the average price of the district. The construction area of CITIC Mangrove Bay is similar to that of Cuihu Xiangshan Apartment, however, its housing price is as high as $¥ 47,500$ / square meter. As in the above situation, there are many examples of similar building areas but large price gaps. It can be seen that the size of the community does not affect housing prices.

\section{Conclusion and Research Limitations}

\subsection{Conclusion}

Based on the above research results, the paper draws the following conclusions:

1. For Zhuhai Xiangzhou District, the distance from the sea is an important factor affecting housing prices. Sea 
view rooms often have high prices.

2. Due to its special geographical advantage and important economic status, the factors that generally affect housing prices may change when affecting properties in Xiangzhou District.

3. The distance from the Hong Kong-Zhuhai-Macao Bridge, traffic conditions, developer awareness, and the time of driving to the Hong Kong-Zhuhai-Macao Bridge also have a certain impact on the housing prices in Xiangzhou.

\subsection{Limitations and Recommendations}

The sample size of this paper is small, and it is greatly affected by the data of some special buildings, which may be the reason why some variables are not significant. In addition, this article only studies the real estate data of Xiangzhou District, so the research results can not show how various factors affect the prices of Zhuhai City. Finally, this article only selects the housing price data on October and November 2018. Therefore, the time span of the data is small, which does not reflect whether there is any change in the housing prices before and after the completion of the Hong Kong-Zhuhai-Macao Bridge.

This paper has the following recommendations for related research in the future:

1. The geographical scope can be expanded while When studying the impact of the Hong Kong-Zhuhai-Macao Bridge on housing prices. For example, it can be analyzed whether the expressway connected to the Hong Kong-Zhuhai-Macao Bridge will affect housing prices in Doumen District, Jinwan District, or other neighboring areas.

2. Subsequent research can pay more attention to the time span and compare the housing price data before and after the completion of the Hong Kong-Zhuhai-Macao Bridge.

\section{References}

[1] Huang Houxia, Hou Liying. Summary of Housing Price Factors[J]. China Real Estate, 2011(14): 39-44.

[2] Li Chen. Analysis of Factors Affecting China's Housing Price Based on Factor Analysis[J]. Economic Research Guide, 2010(16): 158-159.

[3] Zhang Jiaping. Empirical Study on the Relationship between RMB Exchange Rate Changes and Real Estate Price[J].南金融, 2008(4):14-16.

[4] Yan Lei. Analysis of Factors Affecting Real Estate Price: An Empirical Study Based on Panel Data from 1997 to 2008 [J]. Business Culture (2nd Half Month), 2011(1): 140.

[5] Yao Xianguo, Huang Yuhua. Relationship between land price and house price[J]. China Land, 2001(9): 3335.

[6] Jin Xiaobin, Yin Shaomei, Yin Xiaoning, Zhou Yikang. Research on System Dynamics of Urban Housing Industry Development_— Taking Nanjing as an Example[J]. Journal of Nanjing University(Natural Science), 2004(06): 760-768.

[7] Han Yi. A Brief Discussion on the Impact of Property Management on Real Estate Price[J]. Urban Development, 2004(8): 82-83.

[8] Feng Wen, Hu Wei. Analysis of the Influence of Price Change of Main Building Materials on Housing Price[J]. Construction, 2006, 28(1): 76-78.

[9] Zhang Huawei. Research on the Impact of Hong Kong-Zhuhai-Macao Bridge Construction on Zhuhai Real Estate Industry [J]. Southern Economy, 2014(7): 120-124.

[11] Pan W. A Newer Equal Part Linear Regression Model: A Case Study of the Influence of Educational Input on Gross National Income.Eurasia Journal of Mathematics, Science, and Technology Education.

2017;13(8):5765-5773. 